\title{
Examining and comparing the health and performance indices of university undergraduate students according to year of study and gender
}

\author{
Monday Omoniyi Moses 1,*, Francis Osei', Eric Juniour Appiah', Agnes Obour', Lady Gwendoline Akwa', Biggie Baffour-Awuah', \\ Benjamin Asamoah', Peter Akwasi Sarpong', Caleb Adams', Rosario D'Onofrio² \\ 'Department of Sports and Exercise Science, Faculty of Allied Health Sciences, College of Health Sciences, Kwame Nkrumah University of Science and Technology, Kumasi, \\ Ghana \\ ${ }^{2}$ Scientific Society of Sports Rehabilitation and Posturology, Lazio, Italy
}

This study examined and compared, based on year of study and gender, the health and performance indices of university undergraduate students. Eighty-nine students (mean \pm standard deviation age, $22.47 \pm 2.22$ years) were randomly selected for assessment prior to second semester examination of 2015/2016 academic year. body mass index, resting metabolic rate, visceral fat, skeletal muscle mass, body fat, systolic \& diastolic blood pressure, resting heart rate, upper \& lower body endurance, handgrip strength, and lower back and hamstring flexibility were assessed. The students had sedentary heart rate, low skeletal muscle mass, average upper and lower body endurance, and weak handgrip strength. Significant difference existed in the visceral fat $(P=0.008)$ be- tween third and fourth year students. There were significant gender differences in resting metabolic rate $(P=0.000)$, skeletal muscle mass $(P=0.000)$, body fat $(P=0.000)$, systolic blood pressure $(P=0.001)$, heart rate $(P=0.005)$ and handgrip strength $(P=0.000)$. There are gender differences in association between health and performance indices. Dependable health education and pragmatic involvement of undergraduate university students in structured exercise programmes are recommended.

Keywords: University undergraduate students, Blood pressure, Body composition, Muscular endurance, Flexibility

\section{INTRODUCTION}

Achievement of better health outcome for all citizenry is entrenched in the Ghana Millennium Development Goals (GMDGs) (National Development Planning Commission, 2015). Multidisciplinary and holistic approaches would be needed to accomplish a considerable progress of health and well-being of individuals in a culturally diversified nation (Reid et al., 2000) like Ghana. One of the fundamental approaches will involve the identification of indices/components that are at-risk when health is compromised (Reid et al., 2000). Body composition and cardiorespiratory functioning are some of the significantly indicted health compromised indicators in developing nations (Lee et al., 2011) due to unhealthy life- styles. Also severe cardiovascular diseases and symptoms such as myocardial infarction (within 6 months), coronary heart disease associated with related chest pain, heart valve disorder, cardiomyopathy or other illness causing cardiac insufficiency, untreated and significantly high blood pressure (180/100 mmHg or higher), increased arrhythmias during physical effort and severe anaemia (hemoglobin $100 \mathrm{~g} / \mathrm{L}$ for women and $110 \mathrm{~g} / \mathrm{L}$ for men) have been well reported (Gustavo, 2010; Suni et al., 2009).

Malfunctioning or ineffectiveness in the function of the body systems as a result of the aforementioned illnesses will contribute significantly to suboptimal skill performance (Kalaja, 2012). World Health Organization (WHO) documents that as the main causes of death and disability shift to chronic and non-communi-

\footnotetext{
${ }^{*}$ Corresponding author: Monday Omoniyi Moses

(iD https://orcid.org/0000-0001-5785-9551

Department of Sports and Exercise Science, Faculty of Allied Health Sciences,

College of Health Sciences, Kwame Nkrumah University of Science and

Technology, Kumasi, Ghana

Tel: +233-547336905, Fax +233-322060302, E-mail: mmomoniyi.chs@knust.edu.gh

Received: June 3, 2017 / Accepted: August 10, 2017
}

This is an Open Access article distributed under the terms of the Creative Commons Attribution Non-Commercial License (http://creativecommons.org/licenses/by-nc/4.0/) which permits unrestricted non-commercial use, distribution, and reproduction in any medium, provided the original work is properly cited. 
cable, populations are increasingly facing modern health risks due to physical inactivity; overweight and obesity, and other diet-related factors; and tobacco and alcohol-related risks (WHO, 2009). Understanding the risks to health is key to preventing disease and enhancing motor performance effectiveness (WHO, 2009). Acquisition of knowledge is said to be essential for behaviour modification though not usually enough to make people act (Suni et al., 2009). The university students in the present study are not particularly motivated to change their personality traits because they feel relatively healthy in spite of their unhealthy behaviours like poor dietary habits, physical inactivity, long sitting hours for academic work, bad sleeping patterns, poor posture, and substance abuse. These unhealthy patterns do not match the recommendation documented in literature that every person should perform resistance training exercises for all major muscle groups-upper body, lower body, core, chest, shoulders and arms - 2 to 3 times per week (DeSimone, 2016). The lifestyle of the sampled population did not only qualify for physically inactive for not meeting regular physical activity criteria but fits into sedentary behaviour (SED) level (Hathaway and Liguori, 2017). Reported health problems, which would be inimical to investment in the education of the youth, seen in SED are hypokinetic problems, poor mental health, coronary heart disease, obesity, low back pain, osteoporosis, hypertension, diabetes, and some cancers (Biddle et al., 2010). This pretense predisposes the students to a lifestyle of hesitance to health screening despite low patronage at the recreational facilities on campus. Having realized the need for proactive measures to reduce SED and increase sedentary breaks (Hathaway and Liguori, 2017), this study examined and compared, based on year of study and sex, the health and performance indices of university undergraduate students.

\section{MATERIALS AND METHODS}

\section{Design and subjects}

A cross sectional descriptive research design was adapted for the present study. Eighty-nine students (58 male and 31 female students), mean age 22.47 (standard deviation [SD], 2.22) years were involved in the study. The participants were year one, two, three, and four students who had been in Kwame Nkrumah University of Science and Technology (KNUST), Kumasi for at least one academic semester, without known health condition, non-smokers, not under any medication or illicit drug usage and obvious disability. In 2010, KNUST launched an annual Trade and Technology (TRATECH) fair to build relevant practical projects and re- search works that should solve societal problems. During the 2016 TRATECH show piece of the Department of Sports and Exercise Science, consent of students were sought for assessment on the health and performance indices in this study. The 89 participants who agreed filled an informed consent form and were used for this study. A measurement laboratory room was set up in the KNUST TRATECH building by the Department of Sports and Exercise Science to accommodate measurements of the health and performance indices in this study.

\section{Measurements}

\section{Physical}

The age (years) of the participants were recorded from students' registration file. Weight $(\mathrm{kg})$ and height $(\mathrm{m})$ were assessed with stadiometer (model RGZ-160, Shanghai Maney Medical Technology Co., Ltd, Shanghai, China).

\section{Body composition}

Body mass index, resting metabolism, visceral fat (VF), skeletal muscle, and body fat were assessed with the Omron Body Composition Monitor (BF511, Omron Healthcare, Hoofddorp, The Netherlands). The participants assumed recommended postures of minimal clothing; step on the main unit with dry foot on the foot electrodes and weight evenly distributed; knees and back straight, and look straight ahead. The grip electrodes were held with dry palms horizontally raised and arms extended straight at $90^{\circ}$ angle of the body; gender, age and height were inputted into the monitor using guest mode. The unit was programmed for one-time use without resetting a personal data number. Appropriate instructions were adhered to: step on the measurement platform within about 30 sec after 0.0 was displayed; and pressed palms firmly on the grips electrodes of the display unit. Displayed value of the participants' BMI, resting metabolism, VF, skeletal muscle and body fat were read and recorded (Omron Healthcare, 2011).

\section{Cardiorespiratory}

Systolic blood pressure (SBP), diastolic blood pressure (DBP), and resting heart rate (RHR) were measured with Omron blood pressure monitor (M10-IT, Omron Healthcare).

\section{Performance indices}

Participants underwent a 1-min push-ups (rpm) test using American College of Sports Medicine (ACSM) protocol (Pescatello, 2014). This test measures endurance of the upper body muscles (anterior deltoid, pectoralis, and triceps). Male participants 
were instructed to use the standard push-up protocol, whiles the female participants use the modified (bent-knee) technique. The total numbers of push-ups to exhaustion under 1 min were recorded. Wall sit test were used to measure participants' isometric leg strength (lower body endurance). Participants were monitored to stand comfortably with feet approximately shoulder width apart, back against smooth vertical wall, and slowly slide their back down the wall to assume a position with both knees and hips at $90^{\circ}$ angle (thighs parallel with the floor) so that feet is about 1.5 feet away from the wall. Upon assuming this position, they were instructed to hold it and timed to exhaustion using EXTECH digital stopwatch (Model 365510, FLIR Commercial Systems Inc., Exetech, Nashua, NH, USA). Handgrip dynamometer (Model 12-0241 Lite, Fabrication Enterprises Inc., White Plains, NY, USA) was used to measure the strength of the grip-squeezing muscles of the hand according to the guidelines of ACSM (Pes-

Table 1. Descriptive distribution of indices $(n=89)$

\begin{tabular}{lccc}
\hline Variable & Mean \pm SD & Skewness & Rating \\
\hline Age $(\mathrm{yr})$ & $22.47 \pm 2.22$ & 1.228 & $\mathrm{NA}$ \\
Height $(\mathrm{m})$ & $1.83 \pm 1.53$ & 9.221 & $\mathrm{NA}$ \\
Weight $(\mathrm{kg})$ & $66.44 \pm 11.60$ & 1.010 & Healthy \\
Body mass index $\left(\mathrm{kg} / \mathrm{m}^{2}\right)$ & $23.33 \pm 3.47$ & 0.832 & Healthy \\
Resting metabolic rate $(\mathrm{kcal} / \mathrm{day})$ & $1,524.14 \pm 203.89$ & 0.486 & Healthy \\
Visceral fat $\left(\mathrm{cm}^{2}\right)$ & $4.82 \pm 2.82$ & 1.313 & Healthy \\
Skeletal muscle mass $(\%)$ & $36.37 \pm 8.41$ & -0.325 & Low \\
Body fat $(\%)$ & $23.21 \pm 11.77$ & 0.388 & Healthy \\
Systolic blood pressure $(\mathrm{mmHg})$ & $112.4 \pm 16.15$ & -0.442 & Healthy \\
Diastolic blood pressure $(\mathrm{mmHg})$ & $68.42 \pm 9.36$ & 0.392 & Healthy \\
Heart rate $(\mathrm{bpm})$ & $76.03 \pm 13.40$ & 2.225 & Sedentary \\
Upper body endurance $(\mathrm{rpm})$ & $22.58 \pm 12.47$ & 1.524 & Average \\
Lower body endurance $(\mathrm{sec})$ & $61.02 \pm 2.61$ & 7.914 & Average \\
Handgrip strength $(\mathrm{kg})$ & $46.46 \pm 22.00$ & 0.287 & Weak \\
Lower back and hamstring & $9.57 \pm 8.39$ & -0.411 & Good \\
$\quad$ flexibility $(\mathrm{cm})$ & & &
\end{tabular}

All variables are positively skewed except skeletal muscle mass, systolic blood pressure, and lower back and hamstring flexibility.

SD, standard deviation; NA, not applicable. catello, 2014). Three trials were observed for both dominant and nondominant hands. The sum of the values obtained for both dominant and nondominant hands were divided by two and recorded as handgrip strength $(\mathrm{kg})$. The acuflex I Modified sit and reach test box (Model 01285B, Novel Products, Inc., Rockton, IL,USA) was used to measure lower back and hamstring flexibility (LBHF) (Hoeger et al., 1990). Average of two trials was recorded in centimeters.

\section{Statistical analysis}

Data collected were inputted IBM SPSS Statistics ver. 23.0 (IBM Co., Armonk, NY, USA) for analysis. Results of mean, standard deviation, and skewness (Table 1), One-way analysis of variance (ANOVA) with post hoc (Tables 2, 3), Independent sample $t$-test (Table 4) and pearson product moment correlation (PPMC) (Table 5) were used for analytical comparison. Levels of significance were set at $P<0.05$ and $<0.01$ (2-tailed).

\section{RESULTS}

The total sample population $(\mathrm{n}=89)$ in the study has mean age of 22.47 (SD, 2.22) years, 5 (5.6\%) were first year students, second year were $14(15.7 \%)$, those in third year were 38 (42.7\%) while final year were 32 (36.0\%). Male student were 58 (65.2\%) and female 31 (34.8\%). Information in Table 1 displays negative skewness in skeletal muscle mass, SBP and lower back and hamstring of the participants and how they stand based on rating when compared with standard normative values.

ANOVA result reveals VF as the only variable with significant difference $(F[3,89]=89.991$, mean difference, $2.15625 ; 95 \%$ confidence interval, $0.3212-3.9913 ; P<0.05)$ according to the year of schooling with specific indicator between third and final year $(P=0.014)$ (Tables 2,3$). T$-test comparison indicates significant difference in resting metabolic rate $(t=8.679, P=0.000)$, skeletal muscle mass $(t=14.280, P=0.000)$, body fat $(t=-10.199$, $P=0.000)$, SBP $(t=3.441, P=0.001)$, RHR $(t=-2.9033 .441$,

Table 2. One-way analysis of variance of indices among years in school

\begin{tabular}{lrrrrrrrrrrrrrr}
\hline & Weight & BMI & RMR & VF & SMM & BF & SBP & DBP & HR & UBE & LBE & HS & LBHF \\
\hline SS & 577.085 & 87.883 & $127,873.663$ & 89.991 & 244.452 & 601.802 & 151.041 & 388.994 & 80.467 & 90.413 & 9.203 & $1,461.275$ & 321.469 \\
MS & 192.362 & 29.294 & $42,624.554$ & 29.997 & 81.484 & 200.601 & 50.347 & 129.665 & 26.822 & 30.138 & 3.068 & 487.092 & 107.156 \\
F-value & 1.451 & 2.559 & 1.026 & 4.172 & 1.156 & 1.471 & 0.187 & 1.502 & 0.145 & 0.181 & 0.411 & 0.946 & 1.533 \\
P-value & 0.234 & 0.060 & 0.385 & $0.008^{*}$ & 0.332 & 0.228 & 0.905 & 0.220 & 0.933 & 0.909 & 0.745 & 0.423 & 0.212 \\
\hline
\end{tabular}

$\mathrm{BMI}$, body mass index; RMR, resting metabolic rate; VF, visceral fat; SMM, skeletal muscle mass; BF, body fat; SBP, systolic blood pressure; DBP, diastolic blood pressure; HR, heart rate; UBE, upper body endurance; LBE, lower body endurance; HS, handgrip strength; LBHF, lower back and hamstring flexibility; SS, sum of square; MS, mean square. ${ }^{*} P<0.05$, significant difference. 
Table 3. Scheffe post hoc analysis on visceral fat

\begin{tabular}{llcccc}
\hline Year (I) & Year $(\mathrm{J})$ & Mean difference $(I-J)$ & SE & Sig. & 95\% Cl \\
\hline First year & Second year & 0.25714 & 1.39697 & 0.998 & -3.7275 to 4.2417 \\
& Third year & 0.40000 & 1.27560 & 0.992 & -3.2384 to 4.0384 \\
Second year & Final year & -1.75625 & 1.28943 & 0.605 & -5.4341 to 1.9216 \\
& First year & -0.25714 & 1.39697 & 0.998 & -4.2417 to 3.7275 \\
& Third year & 0.14286 & 0.83831 & 0.999 & -2.2483 to 2.5340 \\
Third year & Final year & -2.01339 & 0.85921 & 0.148 & -4.4641 to 0.4373 \\
& First year & -0.40000 & 1.27560 & 0.992 & -4.0384 to 3.2384 \\
Final year & Second year & -0.14286 & 0.9389 & -2.5340 to 2.2483 \\
& Final year & $-2.15625^{*}$ & 0.64334 & $0.014^{*}$ & -3.9913 to -0.3212 \\
& First year & 1.75625 & 1.28943 & 0.605 & -1.9216 to 5.4341 \\
& Second year & 2.01339 & 0.85921 & 0.148 & -0.4373 to 4.4641 \\
\hline
\end{tabular}

$\mathrm{SE}$, standard error; $\mathrm{Cl}$, confidence interval.

${ }^{*} P<0.05$, significant difference, $d f=3$.

Table 4. Mean indices differences between male and female

\begin{tabular}{|c|c|c|c|c|c|c|}
\hline Variable & Sex & Mean \pm SD & MD & $95 \% \mathrm{Cl}$ & $t$-test & $P$-value \\
\hline \multirow[t]{2}{*}{ Weight } & $M$ & $68.04 \pm 12.42$ & 4.56 & -0.498 to 9.636 & 1.792 & 0.077 \\
\hline & $\mathrm{F}$ & $63.47 \pm 9.37$ & & & & \\
\hline \multirow[t]{2}{*}{$\mathrm{BMI}$} & $\mathrm{M}$ & $22.93 \pm 3.55$ & -1.14 & -2.669 to 0.380 & -1.492 & 0.139 \\
\hline & $\mathrm{F}$ & $24.07 \pm 3.22$ & & & & \\
\hline \multirow[t]{2}{*}{ RMR } & M & $1,625.12 \pm 170.07$ & 289.89 & 223.50 to 356.28 & 8.679 & $0.000^{*}$ \\
\hline & $\mathrm{F}$ & $1,335.22 \pm 101.98$ & & & & \\
\hline \multirow[t]{2}{*}{ VF } & M & $5.18 \pm 3.31$ & 1.06 & -0.17 to 2.29 & 1.707 & 0.091 \\
\hline & $\mathrm{F}$ & $4.12 \pm 1.33$ & & & & \\
\hline \multirow[t]{2}{*}{ SMM } & M & $41.49 \pm 4.88$ & 14.71 & 12.66 to 16.75 & 14.280 & $0.000^{*}$ \\
\hline & $\mathrm{F}$ & $26.78 \pm 4.09$ & & & & \\
\hline \multirow[t]{2}{*}{$\mathrm{BF}$} & M & $16.89 \pm 7.74$ & -18.12 & -21.66 to -14.59 & -10.199 & $0.000^{*}$ \\
\hline & $\mathrm{F}$ & $35.02 \pm 8.43$ & & & & \\
\hline \multirow[t]{2}{*}{ SBP } & M & $116.46 \pm 12.01$ & 11.67 & 4.92 to 18.41 & 3.441 & $0.001^{*}$ \\
\hline & $\mathrm{F}$ & $104.79 \pm 19.99$ & & & & \\
\hline \multirow[t]{2}{*}{ DBP } & M & $68.72 \pm 9.12$ & 0.85 & -3.31 to 5.01 & 0.407 & 0.685 \\
\hline & $\mathrm{F}$ & $67.87 \pm 9.93$ & & & & \\
\hline \multirow[t]{2}{*}{$H R$} & M & $73.13 \pm 10.19$ & -8.31 & -14.00 to -2.62 & -2.903 & $0.005^{*}$ \\
\hline & $\mathrm{F}$ & $81.45 \pm 16.82$ & & & & \\
\hline \multirow[t]{2}{*}{ UBE } & M & $22.32 \pm 10.05$ & 2.58 & -3.68 to 8.85 & 0.820 & 0.415 \\
\hline & $\mathrm{F}$ & $19.73 \pm 17.70$ & & & & \\
\hline \multirow[t]{2}{*}{ LBE } & M & $120.3 \pm 13.22$ & 0.67 & -0.57 to 1.91 & 1.071 & 0.287 \\
\hline & $\mathrm{F}$ & $60.23 \pm 7.00$ & & & & \\
\hline \multirow[t]{2}{*}{ HS } & M & $57.70 \pm 18.22$ & 32.60 & 24.91 to 40.28 & 8.442 & $0.000^{*}$ \\
\hline & $\mathrm{F}$ & $25.1 \pm 12.88$ & & & & \\
\hline \multirow[t]{2}{*}{ LBHF } & M & $8.00 \pm 8.87$ & -3.65 & -7.38 to 0.08 & -1.944 & 0.055 \\
\hline & $\mathrm{F}$ & $11.74 \pm 7.11$ & & & & \\
\hline
\end{tabular}

$\mathrm{SD}$, standard deviation; MD, mean difference; $\mathrm{Cl}$, confidence interval; BMI, body mass index; RMR, resting metabolic rate; VF, visceral fat; SMM, skeletal muscle mass; $\mathrm{BF}$, body fat; SBP, systolic blood pressure; DBP, diastolic blood pressure; HR, heart rate; UBE, upper body endurance; LBE, lower body endurance; HS, handgrip strength; LBHF, lower back and hamstring flexibility.

${ }^{*} P<0.05$, significant difference, two-tailed, $d f=87$. 
Table 5. Correlation coefficients of indices

\begin{tabular}{|c|c|c|c|c|c|c|c|c|c|c|c|c|c|}
\hline Variable & Value & Weight & BMl & RMR & VF & SMM & $\mathrm{BF}$ & SBP & DBP & HR & UBE & LBE & HS \\
\hline \multirow[t]{2}{*}{ BMl } & $r$ & $0.805^{* *}$ & 1 & & & & & & & & & & \\
\hline & $P$-value & 0.000 & & & & & & & & & & & \\
\hline \multirow[t]{2}{*}{ RMR } & $r$ & $0.808^{* *}$ & $0.466^{* *}$ & 1 & & & & & & & & & \\
\hline & $P$-value & 0.000 & 0.000 & & & & & & & & & & \\
\hline \multirow[t]{2}{*}{ VF } & $r$ & $0.782^{* *}$ & $0.865^{* *}$ & $0.642^{* *}$ & 1 & & & & & & & & \\
\hline & $P$-value & 0.000 & 0.000 & 0.000 & & & & & & & & & \\
\hline \multirow[t]{2}{*}{ SMM } & $r$ & -0.176 & $-0.507^{* *}$ & $0.389^{* *}$ & $-0.272^{*}$ & 1 & & & & & & & \\
\hline & $P$-value & 0.099 & 0.000 & 0.000 & 0.010 & & & & & & & & \\
\hline \multirow[t]{2}{*}{ BF } & $r$ & $0.363^{* *}$ & $0.688^{* *}$ & -0.170 & $0.433^{* *}$ & $-0.921^{* *}$ & 1 & & & & & & \\
\hline & $P$-value & 0.000 & 0.000 & 0.111 & 0.000 & 0.000 & & & & & & & \\
\hline \multirow[t]{2}{*}{ SBP } & $r$ & $0.306^{* *}$ & 0.050 & $0.427^{* *}$ & 0.176 & $0.277^{* * *}$ & -0.115 & 1 & & & & & \\
\hline & $P$-value & 0.004 & 0.644 & 0.000 & 0.099 & 0.009 & 0.283 & & & & & & \\
\hline \multirow[t]{2}{*}{ DBP } & $r$ & $0.221^{*}$ & 0.184 & 0.168 & $0.283^{* *}$ & -0.096 & 0.104 & $0.351^{* *}$ & 1 & & & & \\
\hline & $P$-value & 0.038 & 0.085 & 0.114 & 0.007 & 0.371 & 0.330 & 0.001 & & & & & \\
\hline \multirow[t]{2}{*}{$\mathrm{HR}$} & $r$ & 0.085 & 0.111 & -0.119 & 0.117 & $-0.391^{* *}$ & $0.370^{* *}$ & $0.308^{* *}$ & $0.288^{* *}$ & 1 & & & \\
\hline & $P$-value & 0.431 & 0.299 & 0.267 & 0.274 & 0.000 & 0.000 & 0.003 & 0.006 & & & & \\
\hline \multirow[t]{2}{*}{ UBE } & $r$ & -0.103 & 0.032 & -0.101 & 0.003 & -0.003 & -0.054 & $-0.307^{* *}$ & 0.036 & -0.108 & 1 & & \\
\hline & $P$-value & 0.335 & 0.769 & 0.346 & 0.975 & 0.981 & 0.618 & 0.003 & 0.738 & 0.315 & & & \\
\hline \multirow[t]{2}{*}{ LBE } & $r$ & 0.075 & -0.005 & 0.120 & 0.022 & 0.066 & -0.048 & 0.053 & -0.055 & -0.049 & 0.035 & 1 & \\
\hline & $P$-value & 0.483 & 0.965 & 0.261 & 0.839 & 0.537 & 0.658 & 0.624 & 0.607 & 0.649 & 0.743 & & \\
\hline \multirow[t]{2}{*}{ HS } & $r$ & $0.393^{* *}$ & 0.080 & $0.652^{* *}$ & $0.280^{* *}$ & $0.501^{* *}$ & $-0.405^{* *}$ & $0.213^{*}$ & -0.063 & -0.089 & 0.014 & 0.060 & 1 \\
\hline & $P$-value & 0.000 & 0.454 & 0.000 & 0.008 & 0.000 & 0.000 & 0.045 & 0.557 & 0.405 & 0.898 & 0.577 & \\
\hline \multirow[t]{2}{*}{ LBHF } & $r$ & -0.101 & -0.079 & -0.207 & $-0.220^{*}$ & -0.100 & 0.034 & -0.196 & $-0.241^{*}$ & 0.021 & 0.066 & -0.160 & -0.039 \\
\hline & $P$-value & 0.346 & 0.464 & 0.052 & 0.038 & 0.350 & 0.753 & 0.066 & 0.023 & 0.844 & 0.537 & 0.134 & 0.718 \\
\hline
\end{tabular}

$\mathrm{BMI}$, body mass index; RMR, resting metabolic rate; VF, visceral fat; SMM, skeletal muscle mass; BF, body fat; SBP, systolic blood pressure; DBP, diastolic blood pressure; HR, heart rate; UBE, upper body endurance; LBE, lower body endurance; HS, handgrip strength; LBHF, lower back and hamstring flexibility.

${ }^{*} P<0.05,{ }^{* *} P<0.01$, significant difference, two-tailed.

$P=0.005)$ and handgrip strength $(t=8.442, P=0.000)$ between male and female participants (Table 4).

Results of PPMC analysis conducted among various indices with $P$-values were shown in Table 5 . Body weight and body mass index $(r=0.805, P<0.01)$, resting metabolic rate $(r=0.808$, $P<0.01)$, VF $(r=0.782, P<0.01)$, body fat $(r=0.363, P<0.01)$, $\operatorname{SBP}(r=0.306, P<0.01), \operatorname{DBP}(r=0.221, P<0.05)$, and handgrip strength $(r=0.393, P<0.01)$; BMI and resting metabolic rate $(r=0.466, P<0.01), \mathrm{VF}(r=0.865, P<0.01)$, skeletal muscle mass $(r=-0.507, P<0.01)$, and body fat $(r=0.688, P<0.01) ; \mathrm{RMR}$ and $\operatorname{VF}(r=0.642, P<0.01)$, skeletal muscle mass $(r=0.389, P<0.01)$, SBP $(r=0.427, P<0.01)$ and handgrip strength $(r=0.652$, $P<0.01)$; VF and skeletal muscle mass $(r=-0.272, P<0.05)$, body fat $(r=0.433, P<0.01)$, DBP $(r=0.283, P<0.01)$, handgrip strength $(r=0.280, P<0.01)$, and LBHF $(r=-0.220, P<0.05)$; SMM and body fat $(r=-0.921, P<0.01), \operatorname{SBP}(r=0.277, P<0.01)$, heart rate $(r=-0.391, P<0.01)$, and handgrip strength $(r=0.501$, $P<0.01)$; $\mathrm{BF}$ and heart rate $(r=0.370, P<0.01)$ and handgrip strength $(r=-0.405, P<0.01)$; SBP and DBP $(r=0.351, P<0.01)$, heart rate $(r=0.308, P<0.01)$, upper body endurance $(r=-0.307$, $P<0.01)$ and handgrip strength $(r=0.213, P<0.05)$; DBP and heart rate $(r=0.288, P<0.01)$, and $\mathrm{LBHF}(r=-0.241, P<0.05)$.

\section{DISCUSSION}

This study examined and compared, based on year of study and gender, the health and performance indices of university undergraduate students. Findings showed that the participants are healthy based on the values of weight (Strohacker et al., 2015), BMI (Marlowe et al., 2005) resting metabolic rate (Halson, 2014), VF (Canadian Society for Exercise Physiology, 2010), body fat (Bohannon, 1997), systolic and DBP (WHO, 2009); have good LBHF (Plowman and Meredith, 2013), average upper and lower body endurance (Bohannon, 1997; Brooks, et al., 1996; Reid et al 2000), low skeletal muscle mass (Brooks et al., 1996), weak handgrip strength (Suni et al., 2009) and sedentary heart rate (Faktor, 2009) as seen in Table 1. Although the participants are reported healthy from the values of most the health components measured, 
Table 1 shows that their fitness level observed from performance perspective is substandard. This could be associated with the sedentary nature of their heart rates and also reflects inactive lifestyles of the participants. Physical activity and exercise participation have recorded significant correlation with improved heart rate among various population (Lee et al., 2011).

Authors hypothesized that the number of years spent in school would have reflection on the health and performance indices of university students with significant variation but this assumption is refuted based on our findings. Our finding as discovered in Tables 2 and 3 reveals no significant difference in all variables except VF across years in school. This difference may results from variation in dietary lifestyles (Elhayany et al., 2010). WHO has reported that dietary risk factors such as high blood pressure, cholesterol and obesity, coupled with insufficient physical activity, are responsible for increasing threats to the total disease burden world over (WHO, 2009).

Our findings in Table 4 shows significant differences in resting metabolic rate, skeletal muscle mass, body fat, SBP, heart rate and handgrip strength based on sex. These reiterate earlier scholarly submissions in favour of sex differences in some health and performance components of fitness (Ashwell, 2011; Egwu et al., 2012; Faktor, 2009). There are however no statistically significant differences in body mass index, VF, DBP, upper and lower body endurance as well as LBHF between males and females which supports findings in literature (Ranasinghe et al., 2013a; Reid et al., 2000). It has been argued that the rate of growth of the arm muscle tissues in males during adolescence is approximately twice that in females and that the sex difference in the growth of muscle tissue in the leg is much smaller (Busing and West, 2016). Study shows that sex-related differences in muscular development contribute to differences in physical performance because muscle strength develops in proportion to the cross-sectional area of muscle, and growth curves for strength are essentially the same (Busing and West, 2016).

Table 5 of this study shows positive correlation between body weight and body mass index, resting metabolic rate, VF, body fat, SBP, DBP, and handgrip strength. Positive correlation between body weight and body mass index, VF and body fat has been well documented (Föcker et al., 2015; Ranasinghe et al., 2013b). It has also been generally observed that resting metabolic rate is a function of fat-free mass, fat mass, dietary status and physical activity (Hudson et al., 2013). Outcome of this study reiterates the finding of a study on 145 apparently healthy individuals within age range of 14-18 years that revealed correlation between body mass and blood pressure (Ravisankar et al., 2005). Positive relationship between body weight and handgrip strength supports recent studies on the association between grip strength and blood pressure in adolescents independent of BMI (Dong et al., 2016) as well as relations between extremity muscle strength, respiratory muscle strengths and spirometric measures in a group of male nursing home residents (Bahat et al., 2014). Former study found that increased BMI is associated with enhanced blood pressure and decreased grip strength, but after adjustment for BMI, strong grip strength relates to increase in blood pressure with a concluded that strong grip strength was connected to increased adolescent blood pressure upon modification for BMI while the latter submitted that handgrip strength positively correlates with maximal inspiratory pressure and maximal expiratory pressure. The present study however presents negative significant relationship between skeletal muscle mass and BMI as well as body fat of these sample as noted in other studies (Hasan et al., 2016; Kim et al., 2014).

In this study sample, there was significant negative relationship between DBP and LBHF while the relationship between SBP and LBHF was not significant. This could reflect that BP does not serve as a predisposing agent for increase or decline in LBHF. Although LBHF is a function of muscular movement along the trunk where the heart is anatomically located, LBHF is mostly associated with hamstring muscles: semimembranous, semitendinous, and biceps femoris, located in the back of the thigh with a connection to the lower pelvis of the lower leg (Jandre Reis and Macedo, 2015). This could imply that range of motion at the trunk region of the body may not be majorly required during cardiovascular mechanism for moderate aerobic to high intensity activities of healthy living.

In conclusion, this study presents that university undergraduate students have healthy values of weight, BMI, resting metabolic rate, VF, body fat, systolic and DBP; good LBHF; average upper and lower body endurance; low skeletal muscle mass; weak handgrip strength; and sedentary heart rate. Significant difference was observed only in VF across years in school. There are variations in the differences based on gender and among measured components. Dependable health education and pragmatic involvement of undergraduate university students in structured exercise programme are recommended.

\section{CONFLICT OF INTEREST}

No potential conflict of interest relevant to this article was reported. 


\section{REFERENCES}

Ashwell M. Charts based on body mass index and waist-to-height ratio to assess the health risks of obesity: a review. Open Obes J 2011;3:78-84.

Bahat G, Tufan A, Ozkaya H, Tufan F, Akpinar TS, Akin S, Bahat Z, Kaya Z, Kiyan E, Erten N, Karan MA. Relation between hand grip strength, respiratory muscle strength and spirometric measures in male nursing home residents. Aging Male 2014;17:136-140.

Biddle S, Cavill N, Ekelund U, Gorely T, Griffiths M, Jago R., Jean-Michel O, Monique R, Jo S, Gareth S, Vicente-Rodríguez G, Bryony B, Liz P, Richardson D. Sedentary behaviour and obesity: review of the current scientific evidence. London: Department of Health/Department for Children, Schools and Family; 2010.

Bohannon RW. Reference values for extremity muscle strength obtained by hand-held dynamometry from adults aged 20 to 79 years. Arch Phys Med Rehabil 1997;78:26-32.

Brooks G, Fahey T, White, T. Physiologic responses and long-term adaptations to exercise. In: Brooks GA, Fahey TD, White TP, editors. Exercise physiology: human bioenergetics and its applications. 2nd ed. Mountain View (CA): Mayfield Publishing Co.; 1996. p. 61-77.

Busing K, West C. Determining the relationship between physical fitness, gender, and life satisfaction. SAGE Open 2016;6:1-5.

Canadian Society for Exercise Physiology. The Canadian physical activity, fitness and lifestyle approach supplement to the third edition. Ottawa (ON): Canadian Society for Exercise Physiology; 2010.

DeSimone GT. Muscular strength versus endurance versus power - what is the difference? ACSM's Health Fit J 2016;20:3-4.

Dong B, Wang Z, Arnold L, Song Y, Wang HJ, Ma J. The association between blood pressure and grip strength in adolescents: does body mass index matter? Hypertens Res 2016;39:919-925.

Egwu M, Mbada CE, Olowosejeje D. Normative values of spinal flexibility for nigerians using the inclinometric technique. J Exerc Sci Physiother 2012;8:93-104.

Elhayany A, Lustman A, Abel R, Attal-Singer J, Vinker S. A low carbohydrate Mediterranean diet improves cardiovascular risk factors and diabetes control among overweight patients with type 2 diabetes mellitus: a 1-year prospective randomized intervention study. Diabetes Obes Metab 2010;12:204-209.

Faktor MD. Health-related physical fitness, knowledge and administration of the canadian physical activity, fitness and lifestyle approach. The Faculty of Graduate Studies (Human Kinetics) [master's thesis]. Vancouver (BC): The University of British Columbia, York University; 2009.

Föcker M, Bühren K, Timmesfeld N, Dempfle A, Knoll S, Schwarte R, Egberts KM, Pfeiffer E, Fleischhaker C, Wewetzer C, Hebebrand J, Herpertz-Dahlmann $\mathrm{B}$. The relationship between premorbid body weight and weight at referral, at discharge and at 1-year follow-up in anorexia nervosa. Eur Child Adolesc Psychiatry 2015;24:537-544.

Gustavo NS. Health tourism - The SPA Goers in Portugal. In: Puczkó L, editor. Health, wellness and tourism: healthy tourists, healthy business? Proceedings of the Travel and Tourism Research Association Europe 2010 Annual Conference; 2010 Sept 1-3. Budapest, Hungary.

Halson SL. Monitoring training load to understand fatigue in athletes. Sports Med 2014;44 Suppl 2:S139-147.

Hasan NA, Kamal HM, Hussein ZA. Relation between body mass index percentile and muscle strength and endurance. Egyptian J Med Hum Genet 2016;17:367-372.

Hathaway L, Liguori G. SEDding Ourselves up for problems: the detrimental effects of sedentary behaviour. ACSM's Health Fit J 2017;20:4-6.

Hoeger WW, Hopkins DR, Button S, Palmer TA. Comparing the sit and reach with the modified sit and reach in measuring flexibility in adolescents. Pediatr Exersc Sci 1990;2:156-162.

Hudson LN, Isaac NJ, Reuman DC. The relationship between body mass and field metabolic rate among individual birds and mammals. J Anim Ecol 2013;82:1009-1020.

Jandre Reis FJ, Macedo AR. Influence of Hamstring tightness in pelvic, lumbar and trunk range of motion in low back pain and asymptomatic volunteers during forward bending. Asian Spine J 2015;9:535-540.

Kalaja S. Fundamental movement skills, physical activity , and motivation toward Finnish school physical education: a fundamental movement skills intervention. Jyväskylä: University of Jyväskylä, 2012

Kim TN, Park MS, Ryu JY, Choi HY, Hong HC, Yoo HJ, Kang HJ, Song W, Park SW, Baik SH, Newman AB, Choi KM. Impact of visceral fat on skeletal muscle mass and vice versa in a prospective cohort study: the Korean Sarcopenic Obesity Study (KSOS). PLoS One 2014;9:e115407.

Lee DC, Sui X, Artero EG, Lee IM, Church TS, McAuley PA, Stanford FC, Kohl HW 3rd, Blair SN. Long-term effects of changes in cardiorespiratory fitness and body mass index on all-cause and cardiovascular disease mortality in men: the Aerobics Center Longitudinal Study. Circulation 2011;124:2483-2490.

Marlowe F, Apicella C, Reed D. Men's preferences for women's profile waist-to-hip ratio in two societies. Evol Hum Behav 2005;26:458-468.

National Development Planning Commission. Ghana millennium development goals - 2015 report [Internet]. Accra (Ghana): Republic of Ghana, National Development Planning Commission; 2016 Sep [cited 2016 Jun 25]. Available from: http://www.gh.undp.org/content/dam/ ghana/docs/Doc/Inclgro/UNDP_GH_2015\%20Ghana\%20MDGs\%20 Report.pdf.

Omron Healthcare. Omron instruction manual. Body composition monitor [Internet]. Hoofddorp (The Netherlands): Omron; [2011] [cited 2016 Feb 22]. Available from: https://www.omronhealthcare-ap.com/ 
resources/HBF-214.pdf.

Pescatello LS. ACSM guidelines for exercise testing and prescription. 9th ed. Philadelphia: Wolters Kluwer; 2014.

Plowman SA, Meredith MD. Fitnessgram/activity reference guide. 4th ed. Dallas (TX): The Copper Institute; 2013.

Ranasinghe C, Gamage P, Katulanda P, Andraweera N, Thilakarathne S, Tharanga P. Relationship between body Mass Index (BMI) and body fat percentage, estimated by bioelectrical impedance, in a group of Sri Lankan adults: a cross sectional study. BMC Public Health 2013a;13: 797.

Ranasinghe CD, Ranasinghe P, Jayawardena R, Misra A. Physical activity patterns among South-Asian adults: a systematic review. Int J Behav Nutr Phys Act 2013b;10:116.

Ravisankar P, Madanmohan, Udupa K, Prakash ES. Correlation between body mass index and blood pressure indices, handgrip strength and handgrip endurance in underweight, normal weight and overweight adolescents. Indian J Physiol Pharmacol 2005;49:455-461.

Reid C, Dyck L, McKay H, Frisby W, editors. The health benefits of physical activity for girls and women: literature review and recommendations for future research and policy. Vancouver (BC): British Columbia Centre of Excellence for Women's Health; 2000.

Strohacker K, Fazzino D, Breslin WL, Xu X. The use of periodization in exercise prescriptions for inactive adults: a systematic review. Prev Med Rep 2015;2:385-396.

Suni J, Husu P, Rinne M. Fitness for health: the alpha-fit test battery for adults aged 18-69. Tester' s manual. Tampere (Finland): European Union, DG Sanco \& the UKK Institute for Health Promotion Research; 2009.

World Heath Organization. Global health risks: mortality and burden of disease attributable to selected major risks. Geneva (Switzerland): World Health Organization; 2009. 